\title{
Differential Expression of Synaptic Vesicle Protein 2 (SV2) Isoforms
}

\author{
Sandra M. Bajjalieh, ${ }^{1}$ Gretchen D. Frantz, ${ }^{2}$ James M. Weimann, ${ }^{2}$ Susan K. McConnell, ${ }^{2}$ and Richard H. \\ Scheller ${ }^{1}$ \\ 'Howard Hughes Medical Institute, Department of Molecular and Cellular Physiology, and ${ }^{2}$ Department of Biological \\ Sciences, Stanford University, Stanford, California 94305
}

The synaptic vesicle proteins SV2A and SV2B (SV2 = synaptic vesicle protein 2 ) are two highly related proteins belonging to a family of transporters. As a first step toward identifying the function of the SV2 proteins, we examined the expression of SV2A and SV2B in the rat brain by in situ hybridization, immunohistochemistry, and immunoprecipitation with isoform-specific antibodies. These analyses revealed that one isoform, SV2A, is expressed ubiquitously throughout the brain at varying levels. The other isoform, SV2B, has a more limited distribution with varying degrees of coexpression with SV2A. Immunoprecipitation of brain synaptic vesicles with isoform-specific antibodies followed by Western analyses suggests that both isoforms can be present on the same synaptic vesicle. The expression of the SV2 proteins did not correlate either with neurotransmitter phenotype or with the expression of other synaptic vesicle protein isoforms. SV2B expression was observed to change during development; it is more widely expressed in the immature brain and is found in cells that have yet to establish synaptic contacts. The ubiquitous and overlapping expression of the SV2s suggests that they perform a function common to all synaptic vesicles. Variable and changing coexpression of the SV2 isoforms may indicate that SV2 function is regulated by the isoform composition of synaptic vesicles. The observation that the synaptic vesicle proteins, all occurring in multiple isoforms, are differentially expressed with respect to each other indicates that up to 90 different vesicle types are possible.

[Key words: synaptic vesicles, SV2, vesicular transporters, gene expression, development]

The identification and molecular characterization of proteins specific to synaptic vesicles are a first step toward understanding the molecular events of neurotransmitter release. The major protein constituents of synaptic vesicles have been characterized (reviewed in Jahn and Sudhof, 1993; Walch-Solimena et al., 1993; Bennett and Scheller, 1994), and attention is now turning to the role each plays in neurosecretion.

A synaptic vesicle-associated antigen denoted SV2 (for synaptic vesicle protein 2 ) was identified with a monoclonal antibody generated against cholinergic vesicles from the electric

\footnotetext{
Received Jan. 21, 1994; accepted Mar. 24, 1994

This work was supported by NIH EY06342 (G.D.F.), Damon Runyon-Walter Winchell Cancer Research Fellowship DRG1217 (J.M.W.), and Pew Scholars Award (S.K.M.).

Correspondence should be addressed to Richard Scheller at the above address. Copyright (C) 1994 Society for Neuroscience $0270-6474 / 94 / 145223-13 \$ 05.00 / 0$
}

organ of the electric fish Discopyge ommata. Early biochemical characterization revealed that the SV2 antigen is part of a synaptic vesicle membrane glycoprotein present in all neural and endocrine cells surveyed (Buckley and Kelly, 1985). cDNAs encoding two proteins recognized by the anti-SV2 antibody have been isolated from rat (Bajjalich ct al., 1992, 1993; Feany ct al., 1992). The amino acid sequences of the SV2 proteins are $65 \%$ identical and $\sim 80 \%$ similar (Fig. 1). These proteins, denoted SV2A and SV2B, demonstrate significant homology to a large family of transporter proteins (Henderson and Maiden, 1990; Henderson, 1993). The homology to transporters suggests that the SV2 proteins are synaptic vesicle-specific transporters.

Two members of the transporter superfamily to which SV2 belongs are vesicular neurotransmitter transporters (Linial, 1993); one transports amines (Erickson et al., 1992; Liu et al., 1992), and the other is presumed to be the vesicular transporter of acetylcholine (ACh) (Alfonso et al., 1993). While the amino acid sequences of these transporters are not significantly similar to SV2, their membership in the same family suggests that the SV2 proteins could be vesicular neurotransmitter transporters. Four different transporter activities have been described (reviewed in Edwards, 1992): one for ACh (Marshall and Parsons, 1987), one that appears to transport the biogenic amines serotonin, dopamine, epinephrine, and norepinephrine (Stern-Bach et al., 1990; Isambert et al., 1992), one that appears to transport the inhibitory amino acids GABA and glycine, and a fourth activity that is specific for the excitatory amino acid glutamate (Burger et al., 1991). All of these transport activities require an electrochemical gradient that is generated in vesicles by a $\mathrm{H}^{+}$-ATPase (Anderson et al., 1982; Maycox et al., 1988; Hell et al., 1990). However, they can be distinguished by their sensitivity to different inhibitors and differential requirements for different components of the electrochemical gradient. These unique properties, together with the molecular characterization of amine and ACh-specific vesicular transporters, support the hypothesis that these four transport activities are performed by four distinct molecules.

To begin to understand the function of the SV2 proteins in neurons, we examined the localization of SV2A and SV2B in the rat CNS by in situ hybridization, immunohistochemistry, and immunoprecipitation of purified synaptic vesicles. We addressed the following questions. (1) Is SV2 present in all wellrecognizable brain structures and/or neuronal subtypes? (2) Do individual neurons express only one SV2 isoform? (3) Does the expression of either SV2 isoform correlate with neurotransmitter phenotype? (4) Does the expression of the SV2 isoforms correlate with the expression pattern of any of the other synaptic vesicle protein isoform expression patterns? Our results indicate 


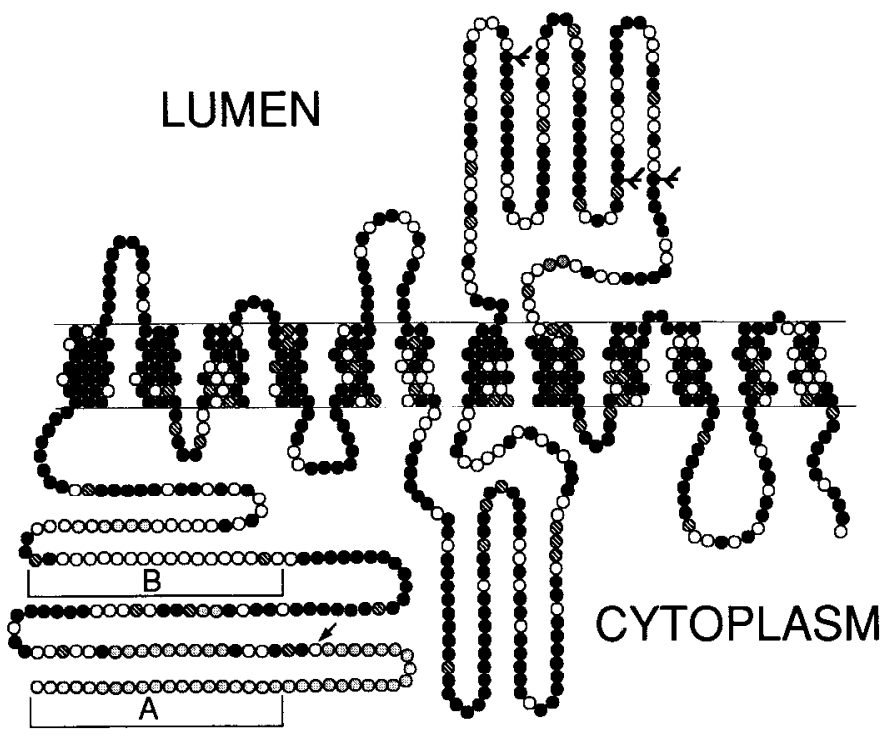

Figure 1. The predicted topology of the SV2 proteins showing regions against which isoform-specific antibodies were generated. Both SV2 proteins are depicted schematically. Each circle symbolizes an amino acid, with circle shading indicating the degree of relatedness of the amino acid in that position. Solid circles represent amino acids that are identical in the two proteins, hatched circles indicate conservative differences, open circles represent nonconservative differences, and stippled circles represent amino acids present only in SV2A. The arrow points to the first amino acid of SV2B. The regions of the proteins against which antibodies were directed are bracketed and labeled.

that SV2A is often coexpressed with SV2B, and that differential isoform expression may regulate SV2 functioning.

\section{Materials and Methods}

Generation of isoform-specific antibodies. Peptides corresponding to amino acids $1-19$ of SV2A and amino acids 56-74 of SV2B were synthesized by Bio-Synthesis, Inc., Lewisville, TX. Peptides were constructed with a cysteine on either the C-terminus (SV2A) or N-terminus (SV2B). The peptides were conjugated to BSA utilizing the heterobifunctional coupling compound Sulfo-SMCC (Pierce Chemical Co., Rockford, IL). Gel analysis of the reaction products revealed that no detectable BSA remained unconjugated. Rabbits were given four injections of the conjugated peptides approximately 3 weeks apart, with test bleeds starting after the second injection (Berkeley Antibody Co., Richmond, CA). The initial injection contained $500 \mu \mathrm{g}$ of protein; all following injections contained $250 \mu \mathrm{g}$.

Sera were tested for the presence of specific antibodies by Western analysis of cellular homogenates from COS cells transfected with either a control plasmid, SV2A, or SV2B. Sera were obtained $19 \mathrm{~d}$ after the final injection and purified on peptide affinity columns constructed with Affigel resin (Bio-Rad). All isoform-specific antibodies used for these experiments were from a single affinity purification.

Transfection of COS cells with SV2 CDNA. To obtain SV2A and SV2B protein, $C O S$ cells were transiently transfected as previously described (Bajjalieh et al., 1992) with the pCMV expression vector (Invitrogen) containing either no insert, SV2A, or SV2B. To obtain larger amounts of protein, $15 \mathrm{~cm}$ culture plates were used. Briefly, plates of one-fourth to one-third confluent COS cells were rinsed with serum-free medium and then incubated with $16.5 \mathrm{ml}$ of serum-free medium containing 80 $\mu \mathrm{g} / \mathrm{ml}$ chloroquine, $0.8 \mathrm{mg}$ of DEAE dextran, and $25 \mu \mathrm{g}$ of DNA for 4 $\mathrm{hr}$ at $37^{\circ} \mathrm{C}$. After incubation with DNA, cells were treated for $2.5 \mathrm{~min}$ with DMSO $(10 \%)$ in serum-free medium. $\Lambda$ fter removing the DMSOcontaining medium, serum-containing medium was added and changed the next day. The third day after transfection cells were harvested or analyzed by immunohistochemistry.

Western analyses. Proteins were resolved on 10\% PAGE gels and transferred to nitrocellulose in Tris/glycine with $10 \%$ methanol. Proteins were visualized with Ponceau stain. Blots were blocked in PBS with
0.5\% Tween-20 and 5\% nonfat milk powder. Antibodies were used at the dilutions indicated in the figure legends. The monoclonal antibody that recognizes both forms of SV2 was obtained as protein G-purified $\mathrm{IgG}$ from $\mathrm{BabCo}$ (Richmond, $\mathrm{CA}$ ) that was produced by the hybridoma described by Buckley and Kelly (1985). Anti-synaptotagmin I (p65A) was detected with a monoclonal antibody (Matthew et al., 1981) obtained through BabCo. Anti-synaptophysin was purchased from Boehringer-Mannheim. Horseradish peroxidase-labeled secondary antibodies were used in conjunction with enhanced chemiluminescence (ECL) reagents (Amersham) to detect antibody binding.

Immunolabeling of transfected cells. Transfected cells were fixed with 4\% paraformaldehyde in PBS. Fixed cells were washed three times for $10 \mathrm{~min}$ in PBS with $0.1 \mathrm{M}$ glycine and then permeabilized with $0.4 \%$ saponin in PBS with $2 \%$ normal goat serum, and $1 \%$ bovine serum albumin. Antibodies were applied in permeabilization buffer for 1-2 hr. Anti-SV2A was used at 1:1000 and anti-SV2B at 1:500. After incubation with the primary antibodies, cells were washed in PBS with $0.1 \mathrm{M}$ glycine, and then incubated with fluorescent secondary antibodies (Tago goat anti-rabbit rhodamine-conjugated antibody) diluted 1:100 in permeabilization buffer. Cells were washed in three changes of PBS and coverslipped.

Immunolabeling of tissue. Single labeling of rat brain sections was done as follows. Adult, female rats were anesthetized with AErrane and decapitated. Brains were removed and embedded, unfixed, in Tissue Tek O.C.T. compound (Miles), and then placed on dry ice to freeze. Frozen blocks were stored at $-70^{\circ} \mathrm{C} ; 18 \mu \mathrm{m}$ frozen sections were cut, dried at room temperature, and stored at $-70^{\circ} \mathrm{C}$. Before processing, sections were rehydrated in PBS and fixed with $4 \%$ paraformaldehyde in PBS. Antibodies were applied in permeabilization buffer ( $1 \%$ bovine serum albumin, $2 \%$ normal goat serum, $0.4 \%$ saponin in phosphatebuffered saline) and incubated overnight at $4^{\circ} \mathrm{C}$. The anti-SV2A antibody was used at a 1:500 dilution, and the anti-SV2B antibody was used at a 1:100 dilution. Antibody binding was detected with the $\mathrm{ABC}$ antibody detection kit (Vector Labs, Burlingame, CA).

In situ hybridization. SV2A (clone 3) in pBluescript SK - and SV2B (clone 6B) in pBluescript KS- were cut with NotI and XbaI, respectively. Linearized DNA was transcribed with $T 7$ polymerase to produce sense and antisense cRNA probes as previously described (Frantz et al., 1994). cDNA probes of the same sequences were shown to be isoform specific in Northern analyses (Bajjalieh et al., 1993). The in situ hybridization protocol was a modified version of that of Simmons et al. (1989). Briefly, $10-15 \mu \mathrm{m}$ sections were pretreated with proteinase $\mathrm{K}$ $(3.7 \mu \mathrm{g} / \mathrm{ml})$ followed by acetylation. Following overnight hybridization at $60^{\circ} \mathrm{C}$, sections were treated with ribonuclease $A(5 \mu \mathrm{g} / \mathrm{ml})$. Sections were washed with a high-stringency wash $\left(0.1 \times \mathrm{SSC}\right.$ at $\left.60^{\circ} \mathrm{C}\right)$. Slides were coated with Kodak NTB2 nuclear track emulsion and exposed for $10 \mathrm{~d}$ (antisense probes) or $21 \mathrm{~d}$ (sense probe) before developing. Some sections were stained with cresyl violet to allow visualization of cell nuclei. Four adult rat brains were processed, as were one brain each of postnatal days $1,5,10,11,14,16$, and two of postnatal day 2 rats. Expression was also examined in sections of embryos. Embryonic days 14 (2 animals), $15(1), 16(2), 17(1)$, and 20 (1) were examined. Sections from one adult rat brain were probed with a sense cRNA. This probe did not produce labeling above background.

To analyze the level of antisense probe hybridization, two types of analyses were performed. One was a qualitative analysis of many sections, both sagittal and coronal, that noted the relative amount of label present in different brain structures. For a more quantitative analysis, two near-adjacent sections were compared, one probed for SV2A and one for SV2B. These sections were from the same experiment and were processed identically. Three or four fields of each brain structure were captured at high power and cells were classified as belonging to one of three bins: 0-10 grains over or adjacent to the nucleus (background), 11-20 grains (light label), 21-50 grains (medium label), or greater than 50 grains (intense label). Exceptions to this classification system are noted in the Table 1 notes. The two methods produced similar results.

Vesicle purification. Synaptic vesicles were purified from brain as previously described (Bajjalieh et al., 1992). For experiments with intact vesicles, the preparation was modified so that vesicles were not pelleted during purification. This was done to prevent potential aggregation. Briefly, frozen rat brains were pulverized in liquid nitrogen in a Waring blender. This powder was homogenized in $10 \mathrm{~mm}$ HEPES, pH 7.2, 0.3 M sucrose using a Teflon-glass homogenizer. Homogenate was centrifuged at $100,000 \times g$ for $1 \mathrm{hr}$. The supernatant was centrifuged at $260,000 \times g$ for $2 \mathrm{hr}$ on a step gradient of $0.6 \mathrm{M}, 1.5 \mathrm{M}$ sucrose. The 
Table 1. Distribution of SV2A and SV2B mRNA expression in selected regions of adult rat brain: analysis of antisense labeling

\begin{tabular}{|c|c|c|c|c|c|c|c|c|}
\hline & $\mathrm{SV} 2$ & & & & SV21 & & & \\
\hline & $\% \mathrm{~T}$ & $*$ & $* *$ & $* * *$ & $\% \mathrm{~T}$ & $*$ & $* *$ & $* * *$ \\
\hline Cerebral cortex & 80 & & 40 & 60 & 80 & 42 & 58 & \\
\hline Striatum & 32 & 84 & 12 & 4 & 20 & 100 & & \\
\hline Globus pallidus & 19 & 31 & 46 & 23 & 0 & & & \\
\hline Hippocampus & & & & & & & & \\
\hline CA1 & 90 & 8 & 79 & 13 & 87 & 23 & 70 & 7 \\
\hline $\mathrm{CA} 3$ & 92 & 25 & 25 & 50 & 87 & 13 & 20 & 67 \\
\hline Dentate granule cells ${ }^{a}$ & & & & & & & & \\
\hline Hilus & 33 & 22 & 56 & 22 & 11 & 33 & 33 & 33 \\
\hline Polymorp & 72 & 23 & 65 & 12 & 73 & 6 & 73 & 20 \\
\hline Stratum oriens & 18 & & 25 & 75 & 0 & & & \\
\hline Stratum radiatum & 25 & & 20 & 80 & 0 & & & \\
\hline Thalamus & & & & & & & & \\
\hline Reticular nucleus & 28 & 58 & 42 & & 0 & & & \\
\hline Lateral posterior nucleus & 33 & 74 & 26 & & 32 & 74 & 26 & \\
\hline Ventro-medial nucleus & 16 & 93 & 7 & & 20 & 16 & 84 & \\
\hline Hypothalamic nuclei & 19 & 70 & 30 & & 11 & 73 & 27 & \\
\hline $\begin{array}{l}\text { Superior colliculus } \\
\text { (deep layer) }\end{array}$ & 27 & 45 & 38 & 17 & 11 & 73 & 27 & \\
\hline $\begin{array}{l}\text { Inferior colliculus } \\
\text { (outer layer) }\end{array}$ & 45 & 40 & 47 & 13 & 15 & 53 & 40 & 7 \\
\hline Substantia nigra & & & & & & & & \\
\hline Compacta & 41 & 19 & 20 & 61 & 19 & 65 & 30 & 5 \\
\hline Reticulata & 25 & 48 & 9 & 43 & 1 & & & 100 \\
\hline Cerebellum & & & & & & & & \\
\hline Molecular layer & 39 & 67 & 33 & & 0 & & & \\
\hline $\begin{array}{l}\text { Purkinje cell layer } \\
\text { Granule cell layer }\end{array}$ & 100 & & & 100 & 0 & & & \\
\hline $\mathrm{MO5}^{c}$ & 14 & 50 & 36 & & 24 & & & 100 \\
\hline Facial nucleus $^{c}$ & 30 & 50 & & & 31 & & & 100 \\
\hline
\end{tabular}

Hybridization levels of each probe were compared across different brain regions as described in Materials and Methods. Listed for each region is the percentage of cells labeled (\%T) followed by the percentage of labeled cells with light $(*)$, moderate $\left({ }^{* *}\right)$, or intense $\left(^{* * *}\right)$ levels of labeling. A qualitative analysis of labeling, done with numerous sections, was in agreement with the results reported here (see Materials and Methods). Identifications were based on those defined by Paxinos and Watson (1986).

${ }^{a}$ The large number of closely positioned granule cells in the dentate made grain counts per cell impossible to estimate. Therefore, we compared the number of grains over several fields divided by a rough count of cell nuclei. The SV2A antisense probe produced two- to threefold more average grains/cell than the sense probe. SV2B labeling was no different than that of the control probe.

${ }^{b}$ The number of grains per cell was also difficult to estimate in the granule cell layer of the cerebellum. Therefore, the number of grains over clearly demarcated cells was determined in several ficlds. Both SV2A and SV2B antisense probes produced labeling at least twofold that of the central probe.

cDue to the large size of neurons in the facial and trigeminal nuclei, the number of grains/cell required for inclusion into the different categories was modified. Cells with 50-100 grains were considered to be lightly labeled. Cells with over 200 grains were considered to be intensely labeled.

material at the $0.6 \mathrm{M} / 1.5 \mathrm{M}$ interface was removed and diluted $1: 1$ with buffer. This was centrifuged overnight at $300,000 \times g$ on a cushion of $1.5 \mathrm{~m}$ sucrose. The membranes at the top of the $1.5 \mathrm{~m}$ cushion were collected and used.

Immunoprecipitation of synaptic vesicles. Synaptic vesicles from approximately half a rat brain were incubated for $1.5 \mathrm{hr}$ at $4^{\circ} \mathrm{C}$ in $10 \mathrm{~mm}$ HEPES, $\mathrm{pH} 7.2,0.3 \mathrm{M}$ sucrose, $0.15 \%$ bovine serum albumin, $1.5 \mathrm{~mm}$ $\mathrm{MgCl}_{2}$ (or the same buffer except with $0.14 \mathrm{M}$ potassium acetate, $0.5 \mathrm{M}$ $\mathrm{NaCl}$ instead of sucrose), and an anti-SV2 antibody. For the precipitation of intact vesicles anti-SV2A and anti-SV2B were used at 1:200, and the monoclonal antibody that rccognizes both isoforms was used at 1:33. Protein A-Sepharose, preswollen and preincubated in the same buffer (Pharmacia), was added (approximately $100 \mu \mathrm{l}$ of swollen beads/ reaction) and the mixture incubated for another hour at $4^{\circ} \mathrm{C}$. Beads were pelleted and washed four times in $1 \mathrm{ml}$ of $10 \mathrm{~mm}$ HEPES, pH 7.2, 0.3 M sucrose, and $1.5 \mathrm{mM} \mathrm{MgCl}_{2}$ (or the same buffer except with $0.14 \mathrm{M}$ potassium acetate, $0.5 \mathrm{M} \mathrm{NaCl}$ instead of sucrose); $100 \mu \mathrm{l}$ of SDS-PAGE sample buffer was added to the pelleted beads, and after incubation at room temperature for $>20 \mathrm{~min}$ the soluble proteins were collected; 5 $\mu \mathrm{l}$ samples were used in Western analyses. Similar results were obtained with both high-salt and sucrose-containing incubation and wash conditions.

\section{Results}

\section{Generation of isoform-specific antibodies}

To distinguish between the SV2 proteins, isoform-specific antibodies were generated. The SV2 isoforms differ most at their 


\section{A}

SV2A-pAb
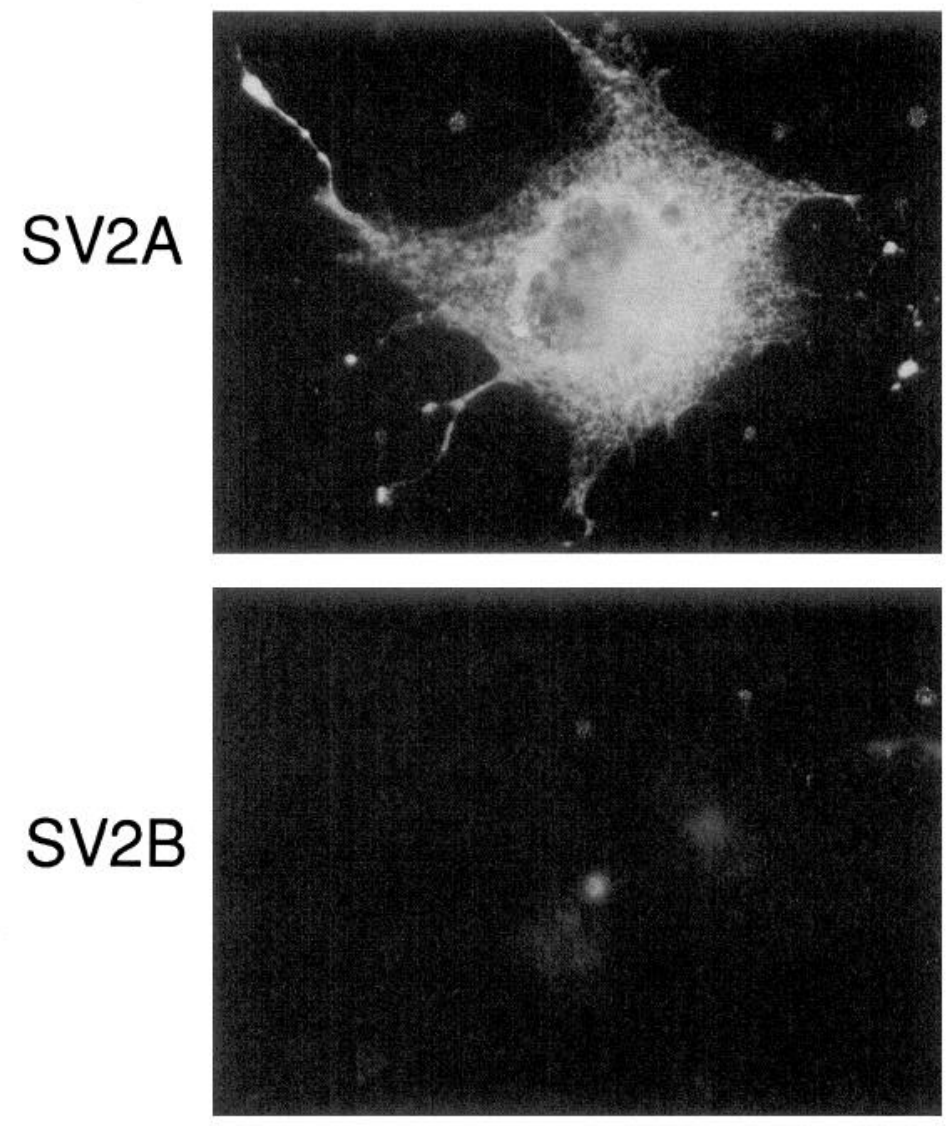

SV2B-pAb
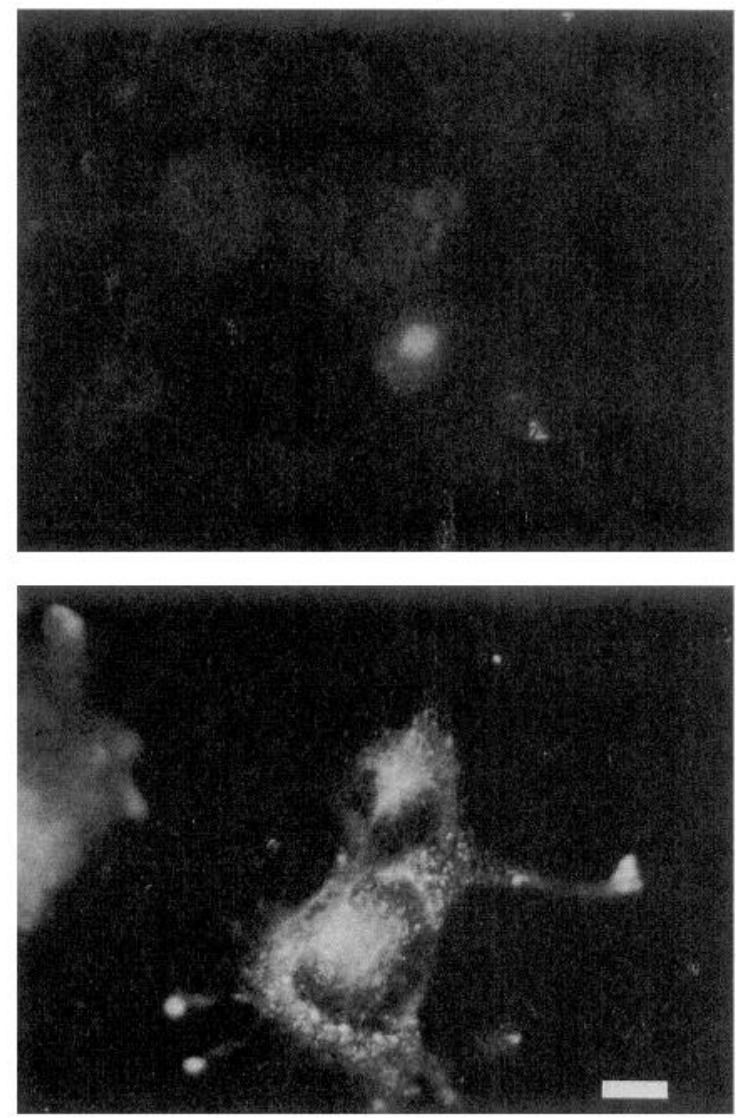

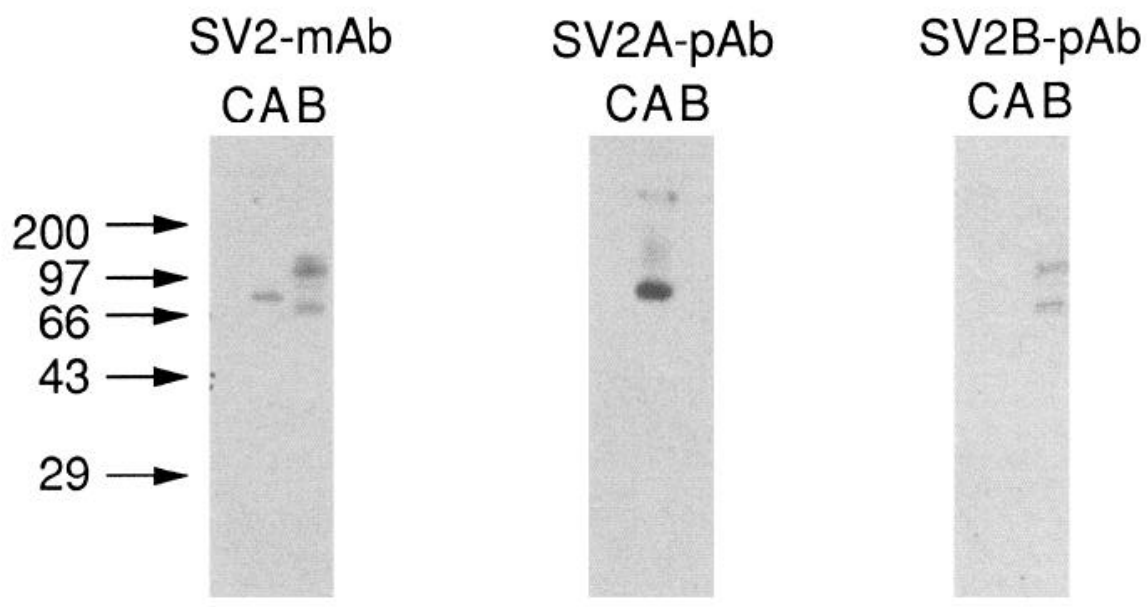

Figure 2. Specificity of the anti-SV2A and anti-SV2B antibodies. The specificity of the anti-peptide antibodies was tested in immunolabeling and Western analyses of COS cells transfected with either SV2A or SV2B. A, Immunolabeling of transfected cells with affinity-purified anti-SV2A polyclonal antibody (SV2A-pAb, 1:1000) or anti-SV2B polyclonal antibody (SV2B-pAb, 1:500). Antibody binding was detected with rhodamineconjugated goat anti-rabbit secondary antibodies. Cells transfected with plasmid vector alone were not immunoreactive (not shown). SV2Atransfected cells labeled with SV2A-pAb but not with SV2B-pAb whereas SV2B-transfected cells labeled with the SV2B-pAb but not SV2A-pAb. Scale bar, $20 \mu \mathrm{m}$. B, Western analysis of transfected cells harvested and processed as described in Materials and Methods. Identical blots were probed with either the anti-SV2 monoclonal antibody that recognizes both isoforms (mAb, 1:1000), anti-SV2A (SV2A-pAb, 1:1000), or anti-SV2B 
amino termini (Fig. 1), although the anti-SV2 monoclonal antibody (Buckley and Kelly, 1985) appears to recognize a cytoplasmic domain in the amino terminus that is common to both isoforms. SV2A is larger than SV2B by 59 amino acids, with all but two of these extra amino acids located near the N-terminus. There is also a stretch of 17 residues in the $\mathrm{N}$-terminus (SV2A amino acids 103-120, SV2B amino acids 56-74) that contains the longest series of nonsimilar amino acids in the two proteins (Fig. 1). We therefore focused on the amino-terminal region for generating isoform-specific antibodies.

Peptides were synthesized corresponding to SV2A amino acids $1-19$, which are unique to SV2A, and to SV2B amino acids 56-74, which contains the 17 amino acid stretch of nonidentical amino acids. Both peptides correspond to regions predicted to be cytoplasmic. Rabbit polyclonal antibodies generated against these peptides were affinity purified on peptide columns. The specificity of these antibodies was assessed both by Western analysis and immunolabeling of COS cells transiently transfected with either the SV2A or SV2B cDNA (Fig. 2). The antibodies were found to be isoform specific in both analyses. As had been previously seen with the anti-SV 2 monoclonal antibody, both polyclonal antibodies produced a reticular labeling pattern in transfected COS cells (Fig. $2 A$ ), confirming the finding that transfected cells segregate both isoforms of SV2 to intracellular membranes (Bajjalieh et al., 1992, 1993). Neither isoform-specific antibody labeled cells transfected with a plasmid that did not contain SV2 (not shown). In Western analyses of cellular material from transfected cells, both antibodies demonstrated the appropriate selectivity (Fig. $2 B$ ).

\section{All brain structures express $S V 2 A$}

In an effort to identify possible transporter functions of the SV2 proteins, we began by examining the regional expression of SV2A and SV2B mRNA and protein within the brain. This survey was done to determine whether SV2 expression was lacking in any brain structure and to ascertain whether the expression of the isoforms was nonoverlapping, which could indicate that the SV2 proteins transport different molecules. The distribution of SV2 mRNAs was determined by in situ hybridization. Protein distribution was determined with the isoform-specific antibodies described above.

In situ hybridization. Hybridization of antisense SV2A and SV2B cRNAs was found throughout the brain (see Fig. 4A,B). All brain structures expressed one or both forms of SV2, consistent with the hypothesis that SV2 is present in all neurons. SV2A was expressed ubiquitously; antisense probe hybridization was detectable in all brain structures with the possible exception of the facial nucleus and the trigeminal nuclei, where labeling was only slightly, though consistently, above background. SV2B expression was more limited; it was undetectable in several brain structures including the dentate gyrus of the hippocampus (compare Fig. $3 C, D$ ), the globus pallidus, reticular nucleus of the thalamus, and the reticular part of the substantia nigra (Fig. 3B). Expression of the two isoforms in selected brain structures examined at higher magnification is listed in Table 1. Both isoforms appeared to be present at roughly the same levels in the cerebral cortex. However, expression levels in other brain structures varicd both within and between probes. For example, both probes intensely labeled the CA3 region of the hippocampus ( $>50 \%$ of the labeled cells had $>50$ grains/cell) whereas the majority of the labeled neurons in the striatum were lightly labeled (11-20 grains/cell) with both probes. In the facial and trigeminal motor nuclei, large neurons were intensely labeled with the anti-SV2B probe ( $>200$ grains/cell). These cells were also labeled with the anti-SV2A probe, but at a level that was only twice background labeling.

Immunohistochemistry. Immunolabeling of the SV2 proteins revealed that both are present throughout the brain (Fig. $3 A^{\prime}, B$ ), although, as with mRNA expression, SV2B immunolabeling was not as widespread as SV2A. As expected for a synaptic vesicle protein, the SV2 proteins were essentially absent from cell body layers, as is illustrated in the hippocampus (Fig. $3 C, D$ ) and cerebellum (Fig. $3 E, F$ ) regions. The pyramidal cell layer of the hippocampus, which is labeled quite heavily with the cRNA probes, essentially lacks protein product, whereas the protein is found in the synaptic layers. This results in an immunolabeling pattern that is roughly the inverse of the in situ labeling. This pattern is particularly apparent in the CA1 region of the hippocampus probed with anti-SV2B (Fig. $3 D$ ): CA1 receives axonal projections from $\mathrm{CA} 3$, which in turn expresses high levels of SV2B mRNA. Interestingly, the SV2B protein is absent from the proximal synaptic regions of CA3. CA3 receives projections from the dentate gyrus, which does not express SV2B mRNA. A similar pattern is seen in the cerebellum, in which the heaviest immunolabeling is found in the synapse-rich molecular layer (Fig. $3 E$, right). In the superior colliculus, a structure that contains layers of synaptic inputs, labeling of SV2A protein had a layered appearance (Fig. $3 A^{\prime}$, arrow). This labeling pattern is consistent with the SV2A protein being concentrated in synaptic regions of this structure.

\section{$S V 2 A$ and $S V 2 B$ expression patterns are inconsistent with either serving as specific neurotransmitter transporters}

The presence of two widely expressed isoforms of SV2 suggests several functional possibilities. One is that the two SV2 proteins might transport distinct amino acid transmitters. Pharmacological characterizations suggest that there are two vesicular amino acid transporters, one for the excitatory amino acid glutamate, and one for the inhibitory amino acids GABA and glycine (Burger et al., 1991). Amino acid transmitters are utilized throughout the CNS and neuroendocrine system, consistent with the expression of the SV2 proteins. If the SV2 proteins are distinct amino acid transporters, their expression would be expected to segregate along excitatory/inhibitory lines in structures where these neurons are spatially separated or easily distinguished. To explore this possibility we examined the expression of SV2 mRNA and protein in the cerebellum, a structure in which excitatory and inhibitory neurons are clearly demarcated.

(SV2B-pAB, 1:500). Lanes $C$ correspond to protein from control cells transfected with vector alone; lanes $A$ correspond to protein from cells transfected with SV2A; lanes $B$ correspond to protein from cells transfected with SV2B. The antibody used in each Western is indicated at the top. Whereas the monoclonal labeled protein from both SV2A or SV2B transfected cells, the isoform-specific antibodies labeled only protein from cells transfected with the same isoform. Multiple immunoreactive bands and smearing of immunoreactivity are common and most likely reflect differences in posttranslational modification and aggregation of the SV2 proteins. 

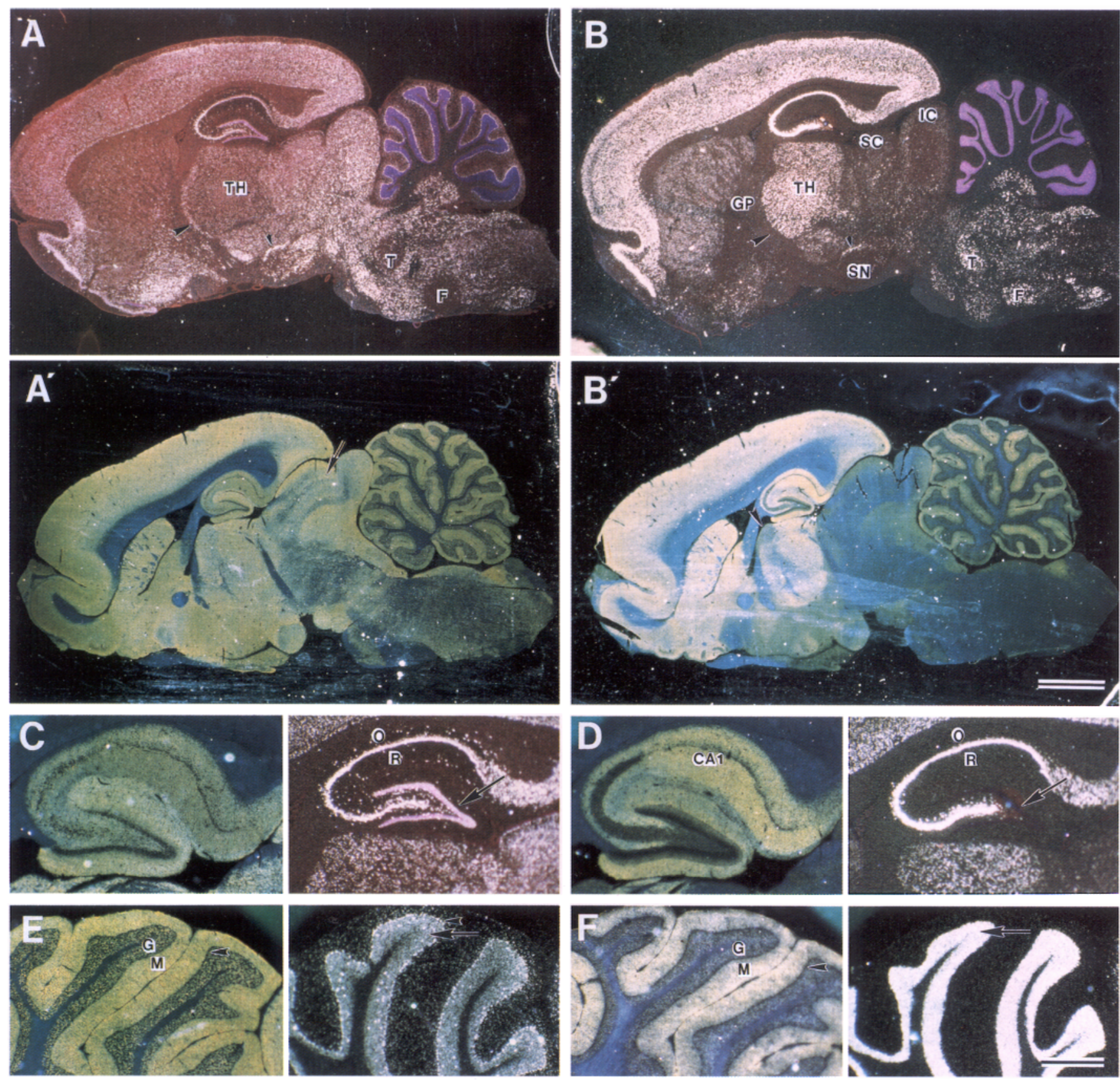

Figure 3. Expression of SV2A and SV2B in adult rat brain: dark-field visualization of in situ hybridization and immunolabeling of SV2A and SV2B in sagittal sections of adult rat brain. By both techniques, SV2A appears to be more broadly expressed than SV2B. A, In situ hybridization of SV2A antisense probe demonstrating the widespread expression of SV2A mRNA. Sections were incubated with radiolabeled probe as described in Materials and Methods. Hybridization of the probe was detected by photographic emulsion. Hybridization signal is visualized as white grains. Cell nuclei were labeled with cresyl violet. TH, thalamus; large arrowhead, reticular nucleus of the thalamus; small arrowhead, substantia nigra, compact part; $T$, trigeminal nucleus; $F$, facial nucleus. $A^{\prime}$, Anti-SV2A immunolabeling visualized by diaminobenzidine (DAB) reaction of horseradish peroxidase-conjugated secondary antibodies. Immunolabel is visualized as a yellow-brown color in dark field. Arrow, laminated labeling of the superior colliculus. B, In situ hybridization of SV2B antisense probe demonstrating that SV2B mRNA expression is less widespread than that of SV2A. Sections were treated as in $A$. Hybridization signal is visualized as white grains. $T H$, thalamus; large arrowhead, reticular nucleus of the thalamus; $G P$, globus pallidus; $S C$, superior colliculus; $I C$, inferior colliculus; $S N$, substantia nigra, reticular part; small arrowhead, substantia nigra, compact part; $T$, motor trigeminal nucleus; $F$, facial nucleus. $B^{\prime}$, Anti-SV2B immunolabeling demonstrating SV2B protein expression. SV2B is found in many brain structures, but is present at lower concentrations in some brainstem structures than SV2A. Arrowhead points to the anterodorsal nucleus of the thalamus, which labeled weakly, suggesting that projections to this nucleus contain primarily SV2A. $C$, High-power view of the hippocampus probed for SV2A. Left, Anti-SV2A immunolabeling demonstrating that SV2A protein is absent from the pyramidal cell body layer and is concentrated in synaptic layers. Right, In situ hybridization of SV2A antisense probe demonstrating that SV2A is expressed by cells in all regions of the hippocampus. Arrow, dentate gyrus; $O$, stratum oriens; $R$, stratum radiatum. Punctate labeling in the stratum oriens and stratum radiatum reflects labeled neurons in those layers. $D$, High-power view of the hippocampus probed for SV2B. Left, Anti-SV2B immunolabeling. SV2B protein is absent from the pyramidal cell body layer of the CA1-CA3 region as expected for a synaptic vesicle protein. Immunolabeling is absent from the CA3 region, which receives projections from the dentate granule cells, and is especially heavy in the synaptic regions of CA1, 


\section{Darkfield}
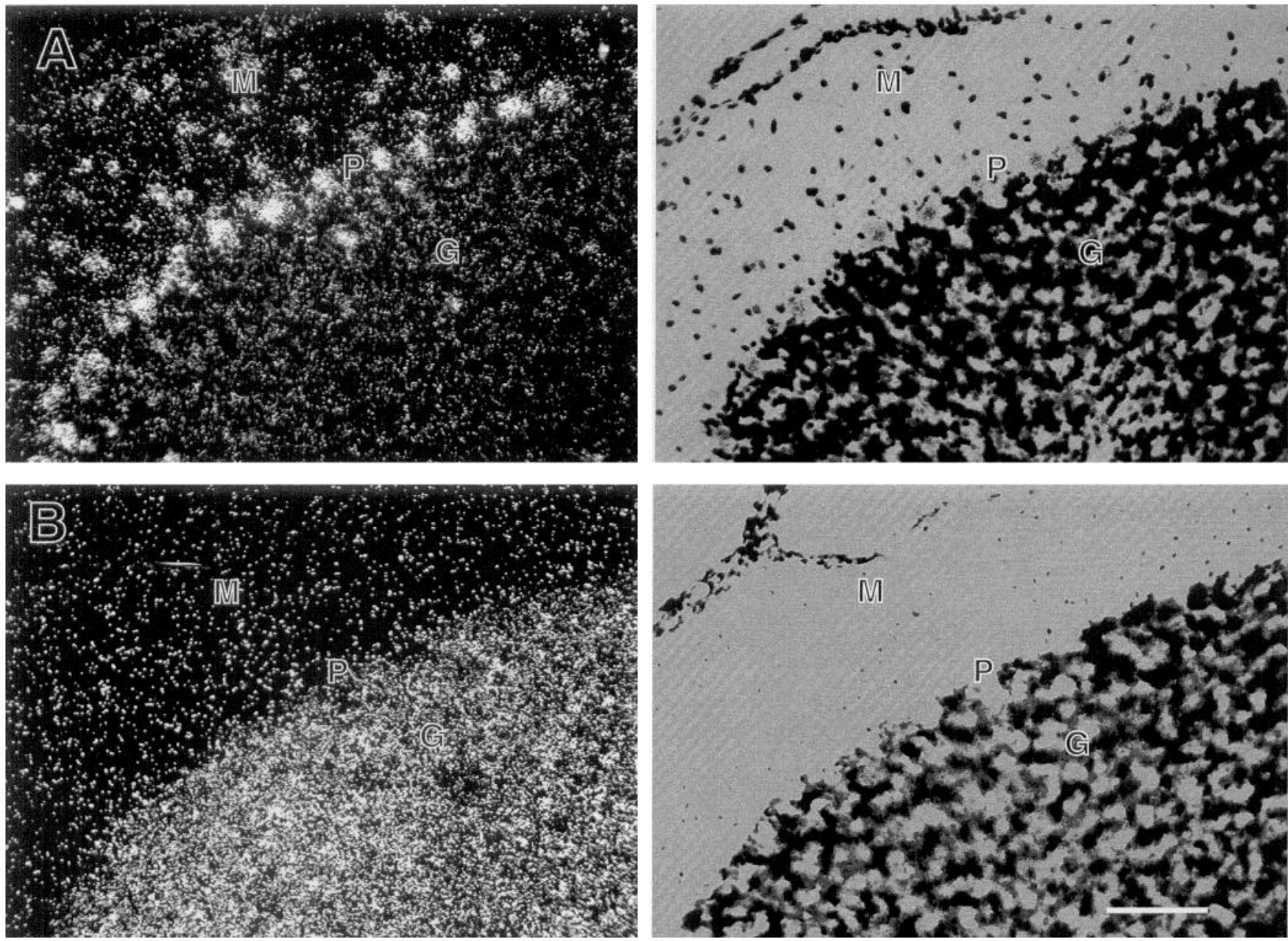

Figure 4. SV2A mRNA expression is not segregated to GABAergic or glutamatergic neurons in the cerebellum: dark-field and bright-field micrographs demonstrating that SV2A is expressed by both GABAergic Purkinje cells and glutamatergic granule cells in the cerebellum whereas SV2B mRNA is expressed only in granule cells. In all fields $M$ indicates the molecular layer, $P$ the Purkinje cell layer, and $G$ the granule cell layer. $A$, SV2A mRNA expression. Dark-field microscopy reveals that all cell layers express SV2A mRNA. Clusters of grains in the molecular layer are over cells. Clusters of grains were also observed over Golgi cells in the granule cell layer. $B$, SV2B mRNA expression. SV2B mRNA is expressed only in granule cells. Scale bar, $50 \mu \mathrm{m}$.

The cerebellum contains three well-distinguished cell layers: an outer molecular layer that contains few cells and many synapses, a single layer of GABAergic Purkinje cells, and an inner layer made up primarily of glutamatergic granule cells (Carpenter, 1991). Figure 4 shows that SV2A was expressed in all types of cerebellar neurons, whereas SV2B was expressed only in the granule cells. Since SV2A is expressed in both GABAergic and glutamatergic neurons, it cannot be a specific transporter for either amino acid neurotransmitter. SV2B expression was limited to the glutamatergic granule cells in the cerebellum. Two other structures containing largely GABAergic neurons, the globus pallidus (Ribak et al., 1979; Ferraguti et al., 1990; Benson et al., 1992; Feldblum et al., 1993), and reticular nucleus of the thalamus (Houser et al., 1980; Ferraguti et al., 1990; Benson et

which receives projections from CA3 neurons. This pattern of protein expression agrees with the expression of SV2B mRNA. Right, In situ hybridization of SV2B antisense probe. SV2B mRNA is present throughout the CA pyramidal cell region with especially high expression in the CA3 pyramidal cell layer but is absent from the dentate gyrus, stratum oriens, and stratum radiatum. Arrow, Dentate gyrus; $O$, stratum oriens; $R$, stratum radiatum. E, Higher-resolution view of the cerebellum probed for SV2A. Left, Anti-SV2A immunolabeling demonstrating that SV2A protein is present in the molecular and granule cell layers, but absent from Purkinje cell bodies as expected for a synaptic vesicle protein. $G$, granule cell layer; $M$, molecular layer. Right, In situ hybridization of SV2A antisense probe. SV2A mRNA is expressed by all cell types of the cerebellum (see also Fig. 4). Arrowhead, Purkinje cell layer; arrow, granule cell layer. F, Higher-resolution view of the cerebellum probed for SV2B. Left, AntiSV2B immunolabeling. SV2B protein is present in the molecular layer, in which granule cell axons terminate and, to a lesser extent than SV2A, in the granule cell layer. SV2B protein in the granule cell layer most likely reflects projections from outside the cerebellum. $G$, granule cell layer; $M$, molecular layer. Right, In situ hybridization of SV2B antisense probe. SV2B mRNA is expressed only in the granule cells (see also Fig. 4). Arrow, granule cell layer. Scale bars: $A$ and $B, 2.5 \mathrm{~mm} ; C-F, 75 \mu \mathrm{m}$. 
Table 2. Distribution of synaptic vesicle protein isoforms

\begin{tabular}{lllll} 
& SV2 & $\begin{array}{l}\text { Synapto- } \\
\text { physin }\end{array}$ & VAMP & $\begin{array}{l}\text { Synapto- } \\
\text { tagmin }\end{array}$ \\
\hline $\begin{array}{l}\text { Telecephalon } \\
\text { Cerebral cortex }\end{array}$ & A/B & I & II & I \\
$\begin{array}{l}\text { Hippocampus } \\
\text { CA1-CA3 }\end{array}$ & A/B & I & II & I \\
$\quad$ Dentate & A & I/II & II & ND \\
Basal ganglia & & & & \\
$\quad$ Caudate putamen & A/B & II & ND & I \\
$\quad$ Globus pallidus & A & I & I & ND \\
Diencephalon (thalamus) & A/B & I & II & I/II \\
Reticular nucleus & A & I & II & ND \\
Midbrain & & & & \\
Superior colliculus & A & I/II & I/II & ND \\
Inferior colliculus & A & I & I/II & ND \\
Substantia nigra & A/B & I & II & ND \\
Cerebellum & & & & II \\
$\quad$ Granule cells & B & I & I/II & I (fish) \\
Purkinje cells & A & I & - & ND \\
Stellate/basket cells & A & I & - & I (fish) \\
Brain stem & & & & II \\
Trigemical nucleus & B & ND & I & ND \\
Facial nucleus & B & ND & I & ND \\
\hline
\end{tabular}

The predominant isoform of the indicated synaptic vesicle proteins is listed for selected brain regions. Synaptophysin (syn I) and synaptoporin (syn II) expression in rat brain was determined by in situ hybridization analysis (Marqueze-Pouey et al., 1991). Synaptotagmin I (p65A) and synaptotagmin II (p65B) expression was determined by immunolabeling of electric fish CNS (Wendland et al., 1991) and Northern analysis of rat brain (Geppert et al., 1991). Expression of VAMP I and VAMP Il in rat brain was surveyed by in situ hybridization (Trimble et al., 1990). Not listed is the expression pattern of rab3. In situ hybridization analyses of rat brain with probes for three rab3 isoforms $(\mathrm{A}-\mathrm{C})$ revealed that rab3A is expressed throughout the brain, whereas expression of the $B$ isoform was seen only in the pituitary and olfactory bulb, and expression of the C form was not detectable (Stettler et al., 1993). ND, not determined.

al., 1992; Feldblum et al., 1993), do not express SV2B. However, the absence of SV2B is not limited to GABAergic neurons. The dentate granule cells, which utilize glutamate, also do not express SV2B mRNA (Fig. 3D). Therefore, the expression pattern of SV2B is also not consistent with its functioning as a specific neurotransmitter transporter.

\section{SV2 isoform expression does not correlate with the expression of other synpatic vesicle protein isoforms}

We examined the possibility that SV2 isoform expression correlates with the expression of other synaptic vesicle protein isoforms. All proteins specific to synaptic vesicles are members of small gene families. It is presumed that the different isoforms of vesicle proteins perform similar or identical functions and that the presence of numerous forms provides a way of finetuning synaptic transmission. To date two isoforms of synaptotagmin (p65) have been found in rat (Geppert et al., 1991) and three in electric fish (Wendland et al., 1991). There are two known isoforms of mammalian VAMP (synaptobrevin) (Elferink et al., 1989) and two forms of synaptophysin (p38) (Knaus et al., 1990). Studies of synaptic vesicle protein isoform expression suggest that all synaptic vesicle proteins are present in a primary, widely distributed isoform whose expression over- laps to varying degrees with a secondary, less broadly distributed form (Trimble et al., 1990; Marqueze-Pouey et al., 1991; Wendland et al., 1991). The differential expression of synaptotagmin and VAMP isoforms appears to have a rostral-caudal pattern, with synaptotagmin A and VAMP II expressed in more rostral brain structures and synaptotagmin B and VAMP I expressed in more caudal brain structures (Trimble et al., 1990; Geppert et al., 1991; Wendland et al., 1991).

We compared previously reported expression patterns of synaptic vesicle protein mRNA to that of SV2A and SV2B and found no striking correlation in the expression of the different isoforms (Table 2). An exception to this is the expression of VAMP I, the less broadly expressed form of the VAMP family (Trimble et al., 1988). Like SV2B, VAMP I is the predominant isoform in the facial nucleus and the trigeminal nuclei. However, with this one exception, the expression of the SV2 isoforms appears to be largely independent of the expression of other synaptic vesicle protein isoforms.

\section{Some neurons express both isoforms of SV2}

The widespread overlap in the expression of the two SV2 isoforms evident at low resolution (Figs. 3, 4) suggested that both isoforms may be present in a single neuron. To address this possibility, we examined the expression of SV2 mRNA in the pyramidal cell layer of the hippocampus, in which both isoforms are expressed. Examination of in situ hybridization in the CA2 region at high resolution revealed that both isoforms are expressed in essentially every cell (Fig. 5). In some cases, neurons that express both isoforms were found to express higher levels of one than the other. An example is seen in large neurons at the periphery of the facial nucleus which express primarily SV2A, whereas large neurons at the center of the nucleus express primarily SV2B (not shown).

\section{Both isoforms may be present on the same synaptic vesicle}

Coexpression of the SV2 proteins may indicate either that the isoforms are on different vesicles within the same neuron, or that both isoforms are present on the same vesicle. To distinguish between these possibilities, we asked whether synaptic vesicles precipitated with an isoform-specific antibody contain both isoforms. Purified rat brain synaptic vesicles were immunoprecipitated with either anti-SV2A, anti-SV2B, or the monoclonal antibody that recognizes both forms. Portions of each precipitation were then assayed by Western analyses for the presence of both isoforms as well as for other synaptic vesicle proteins. Vesicles precipitated with anti-SV2A contained SV2B and vesicles precipitated with anti-SV2B contained SV2A, suggesting that both forms of SV2 are present on some vesicles (Fig. 6). However, anti-SV2A precipitated more SV2A than did anti-SV2B and vice versa, suggesting that many vesicles contain a single or predominant form. Synaptic vesicles precipitated with the isoform-specific antibodies also contained other synaptic vesicle proteins, in addition to the SV2s. Both isoformspecific antibodies precipitated the predominant isoforms of synaptotagmin (p65) and synaptophysin, lending further support to the observation that both SV2 isoforms overlap with all isoforms of other synaptic vesicle proteins.

\section{$S V 2 B$ is expressed early and changes during development}

In situ hybridization analysis of developing embryos and young brain revealed that both isoforms are expressed early in devel- 

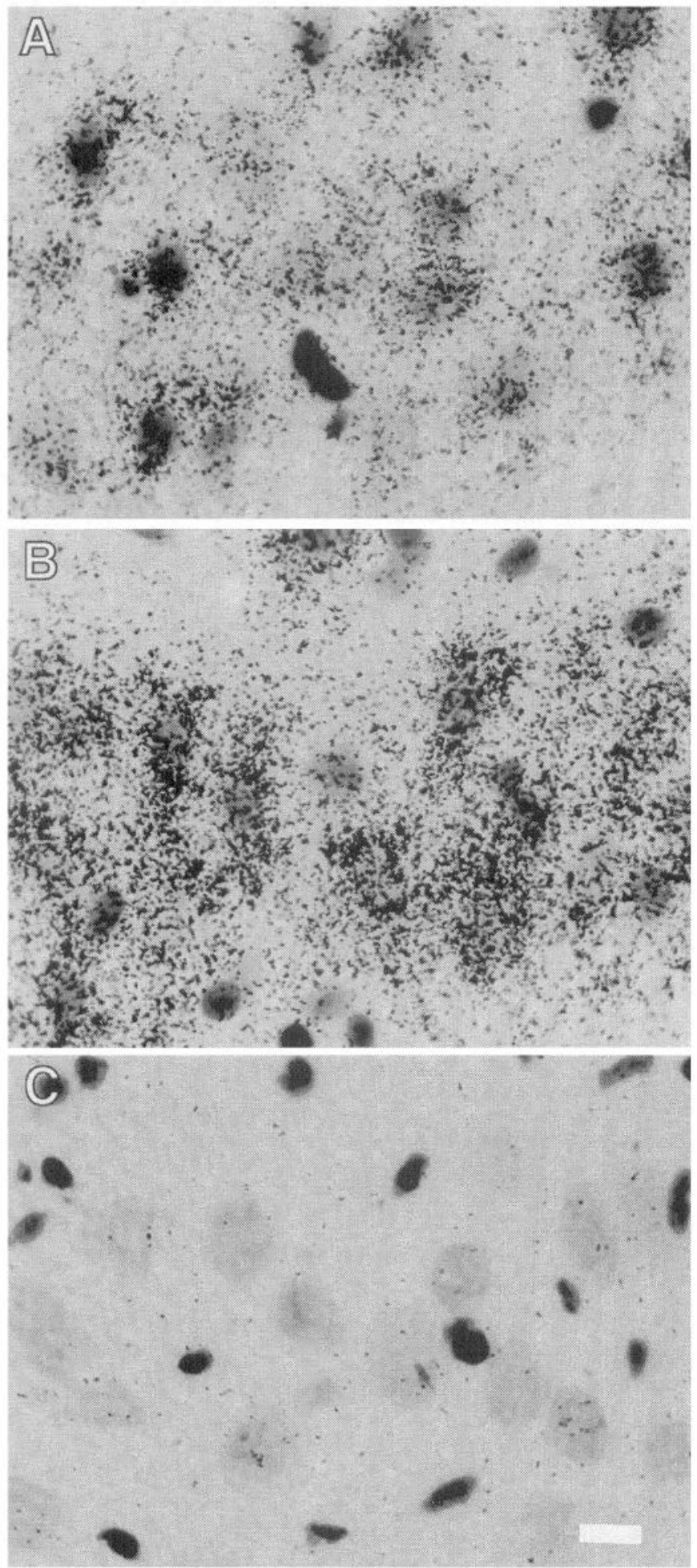

Figure 5. Some neurons express both SV2A and SV2B: Bright-field microscopy of hippocampal pyramidal cells probed for SV2A and SV2B mRNA expression. mRNA expression is indicated by grains over cresyl violet-stained cell nuclei. $A$, SV2A mRNA expression in CA2 pyramidal cells of the hippocampus. Approximately $90 \%$ of the visible cell bodies express SV2A in this region. $B, \mathrm{SV} 2 \mathrm{~B}$ mRNA expression in the identical region as in $A$. Approximately $90 \%$ of the visible cell bodies express SV2B in this region indicating that some cells must express both isoforms. $C$, Control. The identical region as in $A$ and $B$ except probed with SV2A sense cRNA. Emulsion on control sections was exposed twice as long as that on experimental sections. Scale bar, $1 \mu \mathrm{m}$.

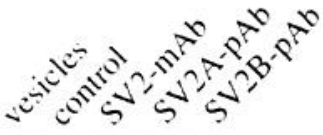

$\mathrm{SV} 2$

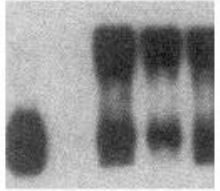

SV2A

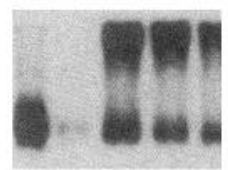

SV2B

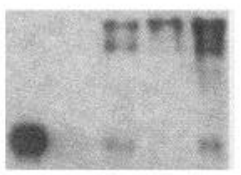

p65A

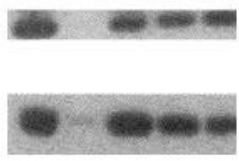

Figure 6. Some synaptic vesicles contain both SV2 isoforms. Synaptic vesicles, purified from rat brain, were immunoprecipitated either with the monoclonal antibody that recognizes both SV2 isoforms, with the anti-SV2A polyclonal antibody, or with the anti-SV2B polyclonal. The precipitating antibody is indicated at the top. A fraction of precipitated material was then probed with the indicated antibodies in Western analyses. The antibody used in each Western analysis is indicated at the left. A volume of synaptic vesicles corresponding to 1/20th (antiSV2 and synaptophysin Westerns) or 1/10 (anti-p65A Western) of the precipitated material was probed as a positive control (labeled vesicles). Control precipitations were Protein A beads, without antibody, incubated with synaptic vesicles. SV2 was probed for with the monoclonal antibody that recognizes both isoforms. SV2A and SV2B were probed for with the polyclonals generated against each of them used at 1:1000 (anti-SV2A) and 1:500 (anti-SV2B). p65A (synaptotagmin I) was probed for with a monoclonal that does not recognize synaptotagmin II (p65B) (Matthew et al., 1981). Synaptophysin (syn I) was probed for with a monoclonal antibody that does not recognize synaptoporin (syn II). The conditions used to prepare the immunoprecipitated material for SDS PAGE cause SV2 to run as a trailing smear, with much of the protein at the top of the gel. The region probed was therefore the entire region above the $66 \mathrm{kDa}$ marker.

opment. Both SV2A and SV2B mRNA were expressed throughout the brain and spinal cord at the earliest time examined (embryonic day 14, not shown) and were expressed at high levels on embryonic day 17 (Fig. $7 A, B$ ). In the developing telencephalon, SV2A mRNA was expressed in all layers of the cerebral cortex (arrow, Fig. 7A) whereas SV2B mRNA expression was limited to the more superficial layers (Fig. $7 B$ ). Interestingly, SV2B expression was also found in the cortical layer of embryonic kidney (Fig. $7 B$, arrow). Expression of either isoform mRNA or protein was absent from adult kidney (not shown). The expression of SV2B in embryonic kidney suggests either that these cells have an endocrine function during development, or that SV2 is transiently expressed in developing exocrine cells. 

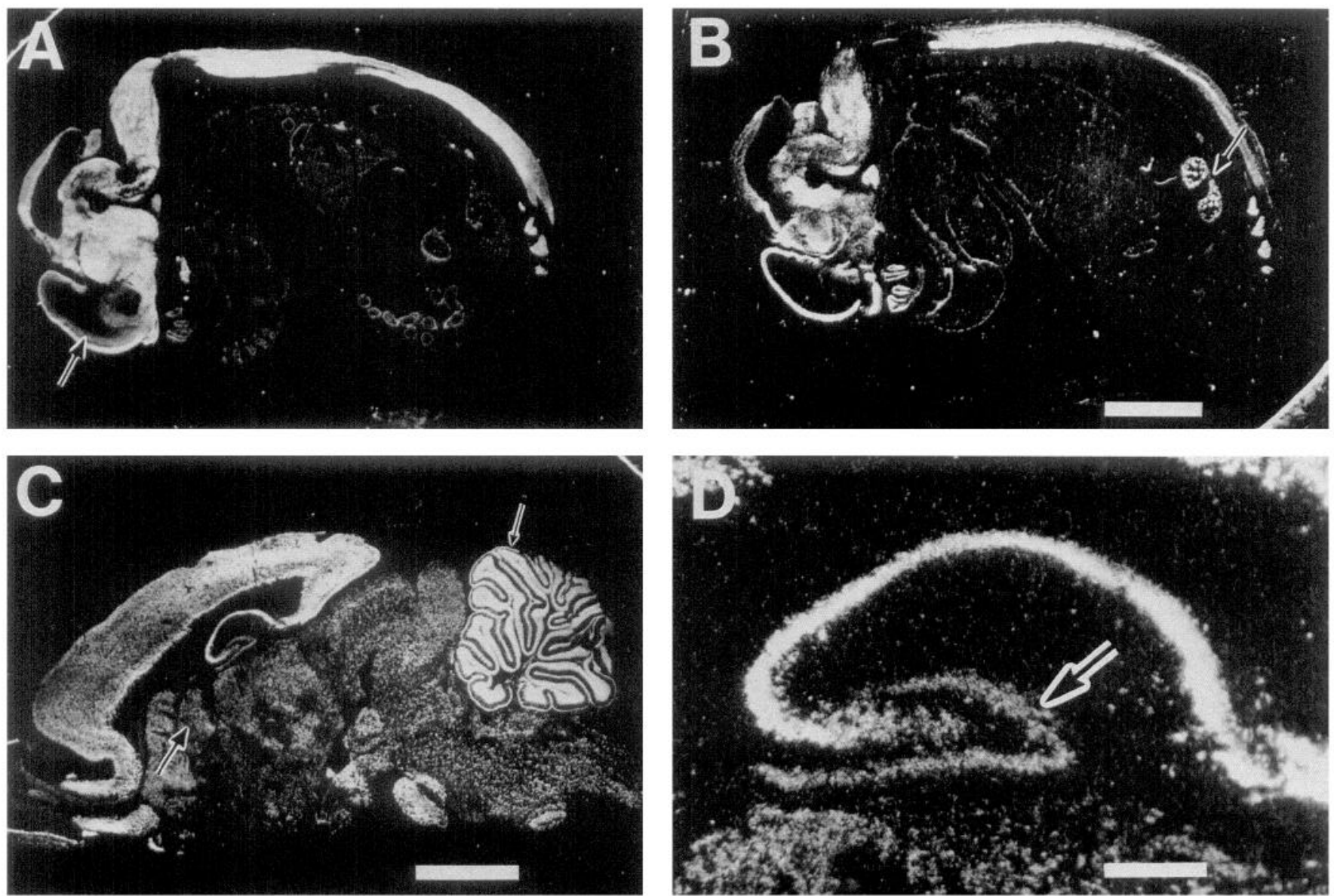

Figure 7. SV2B is more broadly expressed during development: dark-field visualization of in situ hybridization of SV2A $(A)$ and SV2B $(B)$ antisense probes in embryonic day 17 rats and SV2B antisense probes in postnatal day 16 rat brain. $A$, SV2A mRNA expression in embryonic day 17 rat. Hybridization of the antisense probe appears white. Arrow indicates the deeper layers of the developing cerebral cortex. B, SV2B mRNA expression in embryonic day 17 rat. Hybridization of the antisense probe appears white. $C$, SV2B mRNA expression in postnatal day 15 rat brain (sagittal section). Hybridized probe is visualized as white grains. Expression is evident in structures that do not express detectable levels in adult brain, including the globus pallidus (large arrow), and dentate gyrus of the hippocampus. Expression is also seen in the external germinal layer of cerebellum (small arrow). D, Higher power view of SV2B expression in postnatal day 16 rat hippocampus demonstrating that SV2B is expressed in the dentate gyrus (arrow). Scale bars: $A-C, 3 \mathrm{~mm} ; D, 450 \mu \mathrm{m}$.

In situ hybridization analyses of postnatal day (P) 5 through P16 rat brain revealed that the expression of SV2B is broader during development than in the adult. While not detected in the following regions of the adult brain, SV2B was expressed at P16 in the globus pallidus (Fig. $7 C$, large arrow), colliculi (Fig. $7 C$, asterisk), and dentate gyrus of the hippocampus (Fig. 7D). On P5 SV2B expression appeared to be higher relative to other structures in the basal ganglia than at later stages (not shown). The changing pattern of SV2B expression during development is consistent with the idea that the expression of this isoform might be used to regulate SV2 activity.

SV2B, but not SV2A, was expressed in the external germinal layer of the cerebellum (small arrow, Fig. $7 C$ ). Cells in this region are proliferating, extending parallel fibers and beginning their migration to their final position in the granule cell layer. The most superficial layer of the EGL contains cells that are undergoing terminal division before migrating to the granule cell layer (Miale and Sidman, 1961; Fujita, 1967; Rakic, 1971). SV2B is expressed in all layers of the EGL (Fig. 8) suggesting that it is present well before cells have made their first synaptic contacts and perhaps before their final round of cell division.
Cultured neuroblastoma and neuroendocrine cell lines express only $S V 2 A$

Several neuroendocrine cell lines express SV2 and therefore may be good model systems in which to study its function. We surveyed three of these cell lines to determine whether they express one or both forms of SV2. Western analyses of cellular protein revealed that the neuronal cell lines PC12, AtT-20, and the neuroblastoma cell line N1E 115 all express only SV2A and not SV2B (Fig. 9). Therefore, any study of the role of SV2 in these cell lines will be limited to the activity of a single isoform, SV2A.

\section{Discussion}

As a first step toward defining the function of the SV2 family of synaptic vesicle proteins, we have characterized the expression of mRNAs and proteins of the two isoforms. The studies reported here narrow the potential functions of the SV2 proteins by demonstrating that (1) SV2A is expressed, in differing levels, in all brain structures and by all neuronal types surveyed; (2) the expression patterns of the two isoforms do not correlate with either neurotransmitter type or the isoform expression of other 


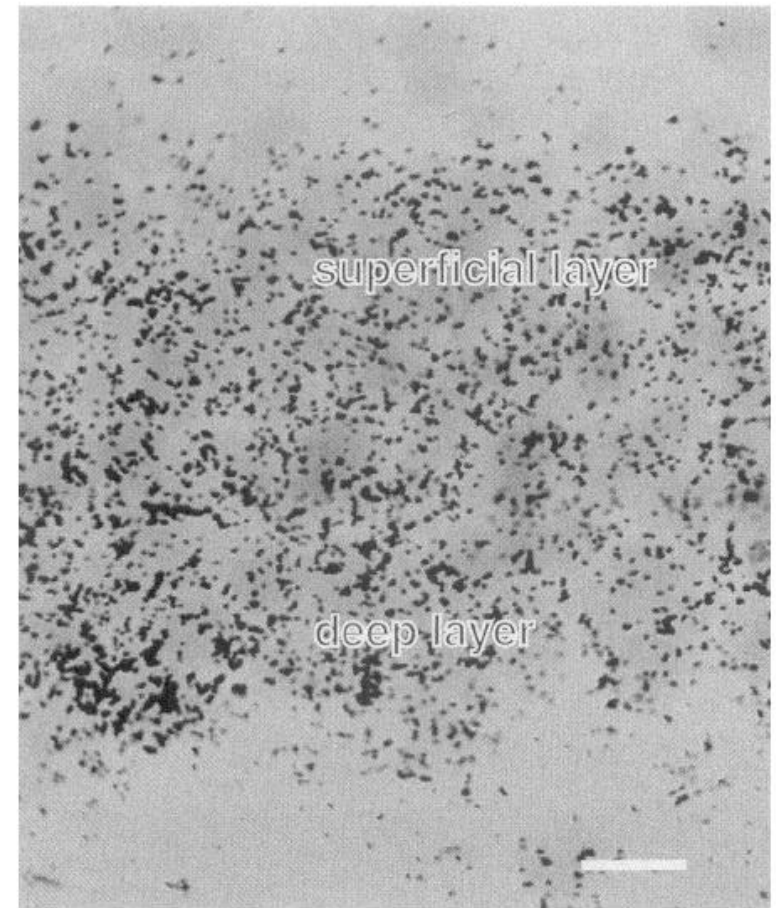

Figure 8. SV2B is expressed in cells that have yet to make synaptic contacts: high-power bright-field view of SV2B antisense probe hybridization in the external germinal layer of the cerebellum at postnatal day 5 . Hybridized probe is visualized as dark grains over cell nuclei stained with cresyl violet. Both the superficial layer, which contains dividing cells, and the deeper layers, which contain cells migrating toward the granule cell layer, are labeled. Unlabeled cells above the superficial layer are cells of the pia mater.

synaptic vesicle proteins; (3) some neurons express both isoforms; and (4) both isoforms may be present in the same vesicle. These observations suggest that the SV2 proteins perform the same function, which is regulated by the isoform content of vesicles. Furthermore, these findings are inconsistent with the possibility that the individual SV2 proteins are transporters for specific neurotransmitters, a function suggested by their homology to the family of transporter proteins that includes the vesicular transporters for amines and acetylcholine.

The absence of SV2B from many GABAergic synapses might indicate that the combination of SV2 proteins in the synaptic vesicle affects neurotransmitter uptake. One way the SV2s might do this is by modulating the electrochemical gradient across the vesicle membrane. Neurotransmitter uptake requires an electrochemical gradient that is produced by an $\mathrm{H}^{+}$-ATPase (Edwards, 1992). The potential (electric) portion of this gradient is dispelled, to some extent, by a concurrent import of chloride and both chloride transport (Xie et al., 1989) and a chloride current (Rahamimoff et al., 1988) have been measured in vesicles. The transport of neurotransmitters is differentially influenced by the composition of the electrochemical gradient (Burger et al., 1991; Edwards, 1992). Variations in chloride transport, which would alter the composition of the electrochemical gradient, may provide a mechanism for regulating neurotransmitter uptake. If the SV2 proteins are chloride transporters, or influence the movement of ions across the vesicle membrane, different amounts and/or combinations of the SV2 proteins could provide such regulation. This hypothesis is consistent with both the differential and overlapping expression of the two isoforms and the absence of SV2B from some GABAergic synapses.

SV2 isoform expression also did not correlate with the expression of any other synaptic vesicle protein isoform. This observation suggests that synaptic vesicles, commonly thought of as homogeneous organelles, are in fact quite varied in their protein composition. If a vesicle can contain one or both forms of SV2, and either form of synaptotagmin, VAMP, synaptophysin, or rab3, numerous different vesicle types are possible. The isoform composition of synaptic vesicles may be a signature of neuronal type or, since the expression of both SV2B and the synaptophysin proteins varies during development, vesicle isoform composition may reflect differences associated with development or with neuronal activity or pathology.

One intriguing exception to this observation is the high level of expression in the motor trigeminal nuclei and facial nucleus of both SV2B and the less broadly expressed form of VAMP, VAMP I. While the significance of this correlation is unknown, it is interesting that both of these nuclei contain large motor neurons that project to muscle.

Many neurons appear to express both isoforms of SV2; furthermore, immunoprecipitations of purified synaptic vesicles suggest that both isoforms may be present on the same vesicle. These observations indicate that the two isoforms probably perform an identical or similar function and suggest that SV2 could exist as a multimer in vivo. Precedence for this is provided by immunoprecipitation experiments with the mammalian facilitative glucose transporters GLUT1 and GLUT4. These transporters, which have significant homology to the SV2 proteins,
SV2A
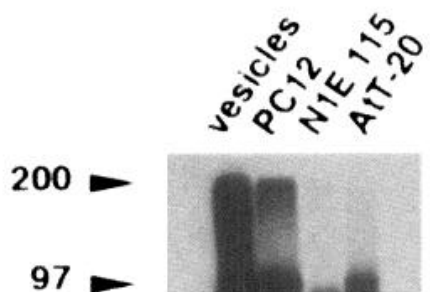

66

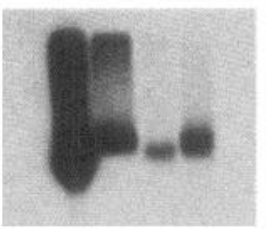

SV2B
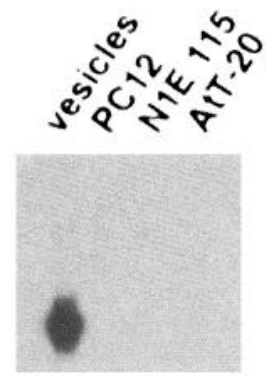

SV2 mAb
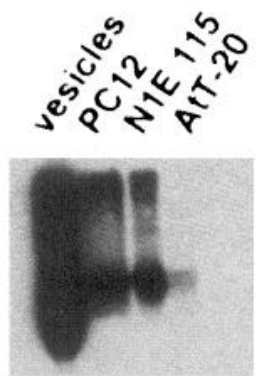

Figure 9. Three neuroendocrine cell lines express SV2A. Three cell lines commonly used in the study of secretion were assayed for SV2A and SV2B. Equal amounts $(50 \mu \mathrm{g})$ of cellular protein from each cell line and $1 \mu \mathrm{g}$ of purified synaptic vesicles were probed with either anti-SV2A (SV2A-pAb, 1:2000), anti-SV2B (SV2B-pAB, 1:500), or the monoclonal that recognizes both isoforms (SV2-mAb, 1:1000). Lanes: PC12 rat transformed adrenal cells grown for at least $3 \mathrm{~d}$ in the presence of nerve growth factor, NIE 115 neuroblastoma cells, At $T$ - 20 cells, a mouse anterior pituitary tumor cell line. 
appear to form homo-oliogomers via interactions between their C-termini (Pessino et al., 1991). If true for the SV2 proteins, isoform composition of SV2 oliogomers may provide a means of modulating transport activity.

The combination of differential and coexpression of the SV2 isoforms suggests that their amount and combination may be tailored to meet individual neuronal needs. This interpretation is especially interesting in light of the observed changes in SV2B expression during development. The globus pallidus and dentate granule cells of the hippocampus, which express SV2B during development, express SV2A both during development and in adulthood. Together with the observation that some synaptic vesicles may express both isoforms, this result indicates that the SV2 isoform composition of synaptic vesicles may vary during development. This variation could provide a means of regulating SV2 activity. Such variations, on a more subtle level, may also accompany changes in synaptic function.

Since the data reported here indicate that the SV2 proteins are not specific neurotransmitter proteins, what other transport role could they play? As discussed above, the SV2 proteins may be chloride transporters. This activity is consistent with the widespread expression of SV2, as chloride transport is required by all synaptic vesicles. Alterna vely, the SV2 proteins may transport another common constituent of synaptic vesicles. Vesicles are known to accumulate calcium and ATP (Kelly and Hooper, 1982). Although transport activity for these molecules has not been reported for vesicles, it may exist. Alternatively, the SV2 proteins may transport an as yet unrecognized vesicle constituent, such as a specific sugar. Or these proteins may serve to move lipids between bilayer leaflets. One interesting, albeit complicated, possibility is that the SV2 proteins move a substrate out of vesicles, perhaps as part of a proteinaceous fusion pore. Such a structure has been hypothesized to mediate the initial, reversible, fusion events observed in studies of exocytosis (Almers and Tse, 1990).

In conclusion, the differential and overlapping expression of the SV2 isoforms suggests that both SV2 proteins perform a similar or identical function generic to synaptic vesicles. These findings raise new questions about the effects of different isoform compositions and how these change with neuronal activity and pathological states.

\section{References}

Alfonso A, Grundahl K, Duerr JS, Han H-P, Rand JB (1993) The Caenorhabditis elegans unc-17 gene: a putative vesicular acetylcholine transporter. Science 261:617-619.

Almers W, Tse FW (1990) Transmitter relcase from synapses: does a preassembled fusion pore initiate exocytosis? Neuron 4:813-818.

Anderson DC, King SC, Parsons SM (1982) Proton gradient linkage to active uptake of ${ }^{3} \mathrm{H}$-acetylcholine by torpedo electric organ synaptic vesicles. Biochemistry 21:3037-3043.

Bajjalieh SM, Peterson K, Shinghal R, Scheller RH (1992) SV2, a brain synaptic vesicle protein homologous to bacterial transporters. Science 257:1271-1273.

Bajjalieh SM, Peterson K, Linial M, Scheller RH (1993) Brain contains two forms of synaptic vesicle protein 2. Proc Natl Acad Sci USA 90: $2150-2154$.

Bennett MK, Scheller RH (1994) A molecular description of synaptic vesicle membrane trafficking. Annu Rev Biochem, in press.

Benson DL, Isackson PJ, Jones EG (1992) Contrasting patterns in the localization of glutamic acid decarboxylase and $\mathrm{Ca}^{2+} /$ calmodulin protein kinase gene expression in the rat central nervous system. Neuroscience 4:825-849.

Buckley K, Kelly RB (1985) Identification of a transmembrane gly- coprotein specific for secretory vesicles of neural and endocrine cells. J Cell Biol 100:1284-1294.

Burger PM, Hell J, Mehl E, Krasel C, Lottspeich F, Jahn R (1991) GABA and glycine in synaptic vesicles: storage and transport characteristics. Neuron 7:287-293.

Carpenter MB (1991) Neuroanatomy. Baltimore: Williams and Wilkins.

Edwards RH (1992) The transport of neurotransmitters into synaptic vesicles. Curr Opin Neurobiol 2:586-594.

Elferink LA, Trimble WS, Scheller RH (1989) Two vesicle-associated membrane protein genes are differentially expressed in the rat central nervous system. J Biol Chem 264:11061-11064.

Erickson JD, Eiden LE, Hoffman BJ (1992) Expression cloning of a reserpine-sensitive vesicular monoamine transporter. Proc Natl Acad Sci USA 89:10993-10997.

Feany MB, Lee S, Edwards RH, Buckley KM (1992) The synaptic vesicle protein SV2 is a novel type of transmembrane transporter. Cell 70:861-867.

Feldblum S, Erlander MG, Tobin AJ (1993) Different distributions of GAD65 and GAD67 mRNAs suggest that the two glutamate decarboxylases play distinctive functional roles. J Neurosci Res 34:689706.

Ferraguti F, Zoli M, Aronsson M, Agnati LF, Goldstein M, Filer D, Fuxe K (1990) Distribution of glutamic acid decarboxylase messenger RNA-containing nerve cell populations of the male rat brain. J Chem Neuroanat 3:377-396.

Frantz GD, Bohner AP, Akers RM, McConnell SK (1994) Regulation of the POU domain gene SCIP during cerebral cortical development. J Neurosci 14:472-485.

Fujita S (1967) Quantitative analysis of cell proliferation and differentiation in the cortex of the postnatal mouse cerebellum. J Cell Biol 32:277-287.

Geppert M, Archer B, Sudhof TC (1991) Synaptotagmin II. A novel differentially distributed form of synaptotagmin. J Biol Chem 266: 13548-13552.

Hell JW, Maycox PR, Jahn R (1990) Energy dependence and functional reconstitution of the gamma-aminobutyric acid carrier from synaptic vesicles. J Biol Chem 265:2111-2117.

Henderson PFJ (1993) The 12-transmembrane helix transporters. Curr Opin Cell Biol 5:708-721.

Henderson PJF, Maiden MCJ (1990) Homologous sugar transport proteins in Escherichia coli and their relatives in both prokaryotes and eukaryotes. Philos Trans R Soc Lond [Biol] 326:391-410.

Houser CR, Vaughn JE, Barber RP, Roberts E (1980) GABA neurons are the major cell type of the nucleus reticularis thalami. Brain Res 200:341-354.

Isambert M-F, Gaasnier B, Botton D, Henry J-P (1992) Characterization and purification of the monoamine transporter of bovine chromaffin granules. Biochemistry 31:1980-1986.

Jahn R, Sudhof TC (1993) Synaptic vesicle traffic: rush hour in the nerve terminal. J Neurochem $61: 12-21$.

Kelly RB, Hooper JE (1982) Cholenergic vesicles. In: The secretory granule. (Poisner and Trifaro, eds). New York: Elsevier.

Knaus P, Marqueze-Pouey B, Scherer H, Betz H (1990) Synaptoporin, a novel putative channel protein of synaptic vesicles. Ncuron 5:453462.

Linial M (1993) Vesicular transporters join the major facilitator superfamily (MFS). Trends Biochem Sci 18:248-249.

Liu Y, Peter D, Roghani A, Schuldiner S, Prive GG, Eisenberg D, Brecha N, Edwards RH (1992) A cDNA that suppresses MPP+ toxicity encodes a vesicular amine transporter. 539-551.

Marqueze-Pouey B, Wisden W, Malosio ML, Betz H (1991) Differential expression of synaptophysin and synaptoporin mRNAs in the postnatal rat central nervous system. J Neurosci 11:3388-3397.

Marshall IG, Parsons SM (1987) The vesicular acetylcholine transport system. Trends Neurosci 10:174-177.

Matthew WD, Tsavaler L, Reichardt LF (1981) Identification of a synaptic vesicle-specific membrane protein with a wide distribution in neuronal and neurosecretory tissue. J Cell Biol 91:257-269.

Maycox PR, Deckwerth T, Hell JW, Jahn R (1988) Glutamate uptake by brain synaptic vesicles. J Biol Chem 263:15423-15428.

Miale I, Sidman RL (1961) An autoradiographic analysis of histogenesis in the mouse cerebellum. Exp Neurol 4:227-296.

Paxinos G, Watson C (1986) The rat brain in sterotaxic coordinates. Orlando, FL: Academic. 
Pessino A, Hebert DN, Woon CW, Harrison SA, Clancy BM, Buxton JM, Carruthers A, Czech MP (1991) Evidence that functional erythrocyte-type glucose transporters are oligomers. J Biol Chem 266:2021320217.

Rahamimoff R, DeRiemer SA, Sakman B, Stadler H, Yakir N (1988) Ion channels in synaptic vesicles from Torpedo electric organ. Proc Natl Acad Sci USA 85:5310-5314.

Rakic P (1971) Neuron-glia relationship during granule cell migration in developing cerebellar cortes. A Golgi and electron microscopic study in Macacus rhesus. J Comp Neurol 141:283-312.

Ribak CE, Vaughn JE, Roberts E (1979) The GABA neurons and their axon terminals in rat corpus striatum as demonstrated by GAD immunocytochemistry. J Comp Neurol 187:261-284.

Simmons DM, Arriza JL, Swanson LW (1989) A complete protocol for in situ hybridization of messenger RNAs in brain and other tissues with radiolabeled single-stranded RNA probes. J Histotech 12:169181.

Stern-Bach Y, Greenberg-Ofrath N, Flechner I, Schuldiner S

(1990)
Identification and purification of a functional amine transporter from bovine chromaffin granules. J Biol Chem 265:3961-3966

Stettler O, Vernier P, Tavitian B (1993) Differential expression of rab3 genes in the rat brain. Eur $\mathrm{J}$ Neurosci, in press.

Trimble WS, Cowan DM, Scheller RH (1988) VAMP-1: a synaptic vesicle-associated integral membrane protein. Proc Natl Acad Sci USA 85:4538-4542.

Trimble WS, Gray TS, Elferink LA, Wilson MC, Scheller RH (1990) Distinct patterns of expression of two VAMP genes within the rat brain. J Neurosci 10:1380-1387.

Walch-Solimena C, Jahn R, Südhof TC (1993) Synaptic vesicle proteins in exocytosis: what do we know? 3:329-336.

Wendland B, Miller KG, Schilling J, Scheller RH (1991) Differential expression of the p65 gene family. Neuron 6:993-1007.

Xie X-S, Crider BP, Stone DK (1989) Isolation and reconstitution of the chloride transporter of clathrin-coated vesicles. J Biol Chem 264 $18870-18873$. 